\title{
INTEGRATIVE APPROACH TO COGNITIVE PARAMETERS IN DECISION MAKING
}

INTEGRAÇÃO DE FATORES COGNITIVOS NA TOMADA DE DECISÃO

Recebido em 20.07.2018. Aprovado em 04.09.2018

Avaliado pelo sistema double blind review

DOI: http://dx.doi.org/10.12712/rpca.v12i4.12613

\section{Roberto Guedes de Nonohay}

roberto.nonohay@imed.edu.br

Faculdade Meridional (IMED), Porto Alegre/RS, BRASIL

ORCID: https://orcid.org/0000-0002-4095-9131

\section{Gustavo Gauer}

gusgauer@gmail.com

Universidade Federal do Rio Grande do Sul (UFRGS), Porto Alegre/RS, BRASIL

ORCID: https://orcid.org/0000-0002-8536-9493

\begin{abstract}
Decisions are pervasive phenomena in everyday life. Two predominant factors in decision-making theory are uncertainty and risk. Nevertheless, there are other cognitive aspects whose roles have recently gained attention in the literature. Those aspects include information acquisition strategies, scenario complexity, the dynamic and/or static aspect of choice scenarios, and the time-frame for the tasks. We propose a selective review and an integrative account as a way to argue for the theoretical importance of logically combining those different factors. The main argument is that the factors involved do not play independent roles, rather they can modulate each other's influence given varying levels of the interactions between factors. The importance of better understanding such interactions lays on the choice of strategies that decision makers use to choose. Finally, theoretical, methodological and managerial contributions and implications relating to such approach are discussed.
\end{abstract}

Keywords: Decision-making. Risk. Uncertainty. Complexity. Information acquisition.

\section{Resumo}

A decisão é um fenômeno pervasivo na vida cotidiana. Dois fatores predominantes na teoria de tomada de decisão são a incerteza e o risco. No entanto, existem outros aspectos cognitivos cujos papéis ganharam atenção na literatura. Esses aspectos incluem a aquisição de informações, complexidade do cenário, o aspecto dinâmico e / ou estático dos cenários de escolha e o tempo das tarefas. Propomos uma revisão seletiva e uma visão integrativa como forma de argumentar a importância teórica de combinar logicamente esses diferentes fatores. $\mathrm{O}$ principal argumento é que os fatores envolvidos não desempenham papéis independentes, ao contrário, podem modular a influência uns dos outros, dados os níveis variáveis das interações entre os fatores. A importância de entender melhor essas interações se baseiam na escolha de estratégias que os tomadores de decisão usam para escolher. Finalmente, as contribuições teóricas, metodológicas e gerenciais e implicações relativas a tal abordagem são discutidas.

Palavras-chave: Tomada de decisão. Risco. Incerteza. Complexidade. Aquisição de informações. 


\section{Introduction}

Decisions range from the mundane, such as choosing among brands of shampoo, to sensitive domains as in medical diagnostics and treatment options. Due to characteristics of the human species' environment and of cognitive processing, decisions involve four key parameters: uncertainty, risk, complexity and satisfaction - or satisficing (Taghavifard, Damghani, \& Moghaddam, 2009; Campbell, 1988; Simon, 1955). At any rate, those key elements suffer a direct influence from environmental factors such as importance, time frame, and individuality degree (Gomes, 2007). All of them, depending on their magnitude, can add to the depletion of much of an individual's cognitive capacity, and in so doing hinder the decision process and its outcome.

Herbert Simon (1955) was among the first scholars to call attention to a linkage between economics and psychology, stating that an understanding of decision processes may actually benefit from studying the agent's behavior. The prevalent idea in the mid 1900 's was that human decision-making was nothing more than an agent's choosing of the alternative that would provide the maximum return possible. That characterizes a normative theory, one that states how the decision should occur in any given scenario. In such case the decision process would be described by a single utility function. That implies that the agent knows all the information available regarding the problem and precisely computes which among the alternatives will maximize the return. That might be true in a few instances, such as in "small world" problems. However, in most cases, individuals do not possess all information, nor do they act according to such paradigm. Uncertainty, the time available, environmental contingencies and limited cognitive capacity often blur the frontiers between what is a real rational choice and a choice based on a subjective account of the world as perceived by the subject (Simon, 1959; Li, Baldassi, Johnson \& Weber, 2013).

Von Neumann and Morgenstern's expected utility theory (1953) was closely related to the rational model described by Simon. It states that the probabilities of the alternatives are actually known, that is, the agent knows the probabilities and the outcomes of every alternative, making the choice process less demanding. That should be as easy as factoring the outcomes weighted by the probability of occurrence. The main problem is that for this theory to be valid, the subject must always acquire and process enough information about the problem, about the environment and about how the environment will respond to the decision that is about to be made. However, that is not the case for most everyday decisions (Brocas, 2012).

Human beings present but a subjective understanding of the world and that understanding varies, sometimes dramatically, from individual to individual. In order to account for such variability, Savage (1955) introduced the concept of Subjective Expected Utility (SEU). The decision maker must choose between certain actions that depend on the occurrence of a given state and will generate a consequence. For each action and each state, the individual will attribute a subjective probability for the outcome. Choosing then comes down to one action being preferred over the other. Subjectivity in a decision scenario can be closely linked to the types of problems and how, and to what level, uncertainty is presented. Simon (1955) stated that each individual possesses a set of preferences and that each decision will be affected by them. An important concept arises, that of satisficing. Each decision is made with a specific goal in mind, be that an objective or subjective one. An individual will come to a decision when a certain threshold is reached. Such threshold can have different values (emotional, financial, etc.) for each person.

Choice problems and scenarios usually present themselves with various degrees of uncertainty and risk (Armbruster \& Delage, 2015; Huang, Liu \& Qi, 2016), which may remain static or can fluctuate up to the point of actual choice. Variations in those degrees can lead to increased complexity in the decision scenario. Uncertainty is common in decisions in ecological settings, and arises when critical information about the situation and the possible choices is unknown, incomplete, or ambiguous. Risk is present in most decisions where individuals have at least some information that makes it possible to state the probabilities of each alternative occurring if chosen. The higher the uncertainty and risk levels, the more cognitive resources an agent must invest in the solution of the problem. Acquiring information is necessary in order to diminish uncertainty and properly weigh risk. The conjunction of the aforementioned factors can modulate or be modulated by inherent or perceived task complexity and/or the decision scenario itself, whether a dynamic or static scenario. Both aspects will significantly affect the decision maker cognitive capacity and may be a hindering effect on the process. 
In many situations, every aspect discussed thus far will have a role in defining and the choice scenario and the decision making steps, sometimes in an integrated fashion.

The present literature typically analyzes those aspects separated or with few of the constructs at once. It is understandable and an operational safeguard to do so. However, we posit that there is a need to better understand the effects of the factors as they play their roles jointly in a given decision scenario, theoretically as it may be. That will provide researchers with a broader theoretical construct as to the different effects that each factor has on a decision. This article aims to propose a theoretical integrated view on the decision-making process and its varying levels of risk, uncertainty and complexity.

\section{Literature Review}

\section{Uncertainty}

Uncertainty can be defined as a common situation with limited calculable information that can appear in different dimensions (Preuschoff, Mohr \& Hsu, 2013), and resolving it is an important trait to successfully engage in adaptive behavior (Bland \& Schaefer, 2012). In the first case, an individual or members of a group simply do not have enough information in order to complete the decision process in a preferable way. That may happen due to faulty information acquisition process (Di Caprio, Santos-Arteaga, \& Tavana, 2014) or if the cost of obtaining the necessary information is too high (Taghavifard et al., 2009). On the other hand, lack of cognition means that the individual or members of a group might possess the necessary information but lack the cognitive capacity for processing and interpreting such information in a way that permits its proper use in the decision-making process.

Levels of information vary within each decision. For a given choice a certain amount of information can be considered optimal for the decision maker to proceed with the analysis (Fific \& Buckmann, 2013; Frey, Hertwig, \& Rieskamp, 2014; Söllner, Bröder, Glöckner, \& Betsch, 2014). Reaching that level provides the individual with a more detailed account of the problem at hand and can facilitate the choice by having more accurate data in order to calculate the possible scenarios and their outcomes. The right amount of information diminishes the levels of residual uncertainty. Residual uncertainty is composed by the facts that remain unknown after the consideration of the possible scenarios is accomplished, once information acquisition and processing is made (Courtney, Kirkland, and Viguerie, 1997).

According to Bland and Schaefer (2012), uncertainty might arise when changes in the prevailing StimulusResponse-Outcome (S-R-O) model is violated. However, that is not the only way, they say, that uncertainty becomes present in a choice. It may also appear when individuals are confronted with problems in obtaining or processing pieces of information, somewhat similar to the levels of uncertainty discussed above.

Meder, Lec, and Osman (2013) discuss the concept of uncertainty from a different perspective. They propose that uncertainty can reside in the agent itself, in other people (as in a group setting), or in the world -as the environment imposes limits of time and resources. Not only are there different sources of uncertainty, but the levels of uncertainty often changes as time passes. One risky decision might have a possible number of outcomes preserved, but the probabilities may change, or both the outcome and the probabilities can be different. In that context, five distinct decisionmaking settings regarding uncertainty are suggested: $i$ ) certainty; ii) risk where the outcome and probabilities are known; iii) a "Black Swan", where there might be an unknown event or events; iv) the Knightian uncertainty, where the outcomes are known but the probabilities are unknown, and v) radical uncertainty, where both outcome and probabilities are unknown.

\section{Risk}

Along with uncertainty, risk is a prominent characteristic of many decision situations. In Knight's (1921) classical definition, risk is a measure of uncertainty where the probabilities of a given outcome are known. Risk is ubiquitous, often serious. It is possible to gain from risks just as much as lose from them. They can help decision makers to decide in uncertain scenarios. With risk individuals are prevented from controlling the outcomes, should they not possess adequate information regarding the problem (Taghavifard et al., 2009).

When individuals are making a decision there are certain probabilities that each alternative may return a given consequence that can be translated into a hazard (harm to somebody or something) or an opportunity 
(Yoe, 2012). A person that drinks alcohol and chooses to drive afterwards has a higher probability of crashing than a person that did not consume alcohol. That is a case in which a hazard might occur. On the other hand, a person that commits years and several amounts of money on education has a greater probability of higher income than a person that did not, hence an opportunity. To assess risk means attempting to determine the outcome of the alternatives available alongside with the probabilities of the consequences they entail. According to Taghavifard et al. (2009), the determination of probabilities is the process of communicating uncertainty between the agents. The sources of uncertainty in that case might come from beliefs, environmental conditions, cognitive capacity, emotions, lack of information, etc.

Taghavifard et al. (2009) propose two opposing poles between which lays risk: ignorance and complete knowledge. Ignorance is equivalent to ambiguity (Camerer and Weber, 1992). A decision scenario where the decision maker has no information or knowledge presents the greater amount of risk given that there is no possibility of actually knowing what might happen. If the decision maker has some knowledge, there is still risk in the situation, but the chance arises to use a probabilistic model (subjective probabilities, bayesian inference, etc.) and calculate the chances of outcomes and consequences. However, if the decision maker has complete knowledge about the scenario and the problem, he or she can use a deterministic model and decide toward the best alternative with maximum return and no risk. In that case risk is absent because complete knowledge allows the individual to know the consequences and probability of occurrence of each alternative. In doing so, if there are no consequences or no probability of them happening, there is no risk.

\section{Information acquisition}

As Taghavifard et al. (2009) discuss, it is only possible to know the risks inherent in a decision if the individual diminishes the residual uncertainty in the scenario (Courtney et al., 1997) through information acquisition. Every day individuals receive a considerable amount of information in many ways, auditory, visual, tactile, and emotional stimuli can all be a source of new information. To acquire information is to search both internally and externally for elements that can affect the decision process. Each piece of information has great importance to the decision maker, either by improving the quality of the decision or by impairing the ability to decide given that the amount of information is so great that the performance will be deteriorated (Di Caprio et al., 2014). When information reveals itself and is processed by the decision maker, it is possible to move from a situation of uncertainty to a situation of risk, that is, the decision maker now knows enough information about the problem and can at least subjectively infer a probability for each outcome (Di Caprio et al., 2014).

Pretz, Naples, and Sternberg (2003) discuss the role of experts and the fact that too much information can actually impair the decision process. An expert possesses a great deal of knowledge, acquired by experience and information gathering. The authors propose that when an expert in chess plays with slightly different rules, the performance will actually be worse than that of a player that is new to chess and plays the same modified game as the expert. Experts are also said to be able to construct a more robust representation of a problem (Maitland \& Sammartino, 2014). However, too much information can become suboptimal for the decision maker (Di Caprio et al., 2014) and not enough information will prevent the decision maker from calculating risks properly and brings the decision process to one state of most uncertainty (Taghavifard et al., 2009). On the other hand, Frey et al. (2014) propose that there is no way to determine when the right amount of information is reached and no further acquisition needs to be done, at least in decisions from experience, although they also say that there may be benefits in small samples and frugal search. The question that remains is, how does a decision maker knows that he/she acquired enough information to go through with the process?

The question above regards information acquisition and when individuals stop searching for information and proceed to a decision. Gigerenzer (2000) proposes a model of "fast and frugal" processes used to decide in environments where both time and knowledge are restricted. By searching past information and knowledge in order to recognize elements regarding the decision and cues about those elements, the Take the Best (TTB) heuristic searches for the best cue in order to make a choice. In the experiments depicted by Gigerenzer (2000) when people where asked which of two German cities was the most populated, it is most likely that an individual will use TTBB if she decides only by the fact that she recognizes one of the cities. Even so, the individual might seek cues about each city 
from memory. According to the subjective validity of the cue, the one with the highest ranking is considered the best and thus appropriate for a decision. Very little information search and acquisition is made and, according to the author, decisions are effective in most attempts.

Stern, Gonzalez, Welsh, and Taylor (2010) conducted and experiment in which individuals were presented with two decks with varying proportions of red and blue cards. Four draws of cards were made and at each draw the individual would have to state from which deck the card had been drawn from. Each draw represented new information about the decision. After all four draws participants would have to make a final decision as to which deck supplied the cards for the draws or they could decline to choose. It is clear that each new information presented changed or reaffirmed the decision made by the individual. When conflicting information was presented (two draws were red cards and two were blue) individuals mostly declined to choose, inferring a $50 \%$ chance to each deck. When all draws were the same color, by the third draw individuals were already confident from which deck the draws were made.

Fific and Buckmann (2013) have probed the use of stopping rules in information acquisition by individuals. Stopping rules might determine the moment where the decision maker stops, or should stop, searching for information and actually decide. The authors reviewed some options of stopping rules that might require higher or lower cognitive demands. The first one is the so-called optimal stopping rule for evidence accumulation. It is based on Bayesian inference and implies that there should be an optimal number of pieces of information that need to be acquired. In the example proposed by Fific and Buckmann (2013), the optimal stopping rule is three. This number represents that the individual will search for positive $(+1)$ and negative (-1) pieces of information and will only stop searching when the sum of the search reaches either +3 or -3 , in which case the individual will choose the option represented by the positive or negative sum, in their example to proceed or not with a risky cancer treatment. This task, however, may not be so easily executed. In order to calculate the optimal number there is a need to have an almost perfect knowledge of the situation and enough calculating skills to solve it through sequential Bayesian probability (Fific \& Buckmann). This option requires great amounts of time, knowledge and cognitive abilities.
In most cases in the real world there are limited amount of each available to the decision maker. Fific and Buckmann (2013) then propose a stopping rule selection theory based on bounded rationality. They suggest two rules that do not depend on high amounts of knowledge about the environment and the situation. The first one is called the fixed sample size. This rule entails that the decision maker will determine a sample size before the beginning of the information search process, for example five. The individual will then search for information and will make a choice based on the valence that appears the most (positive or negative). In this case, if three out of five information are positive, then the individual will accept or decide towards that information. The other one is called runs stopping rule. In this case the decision maker will begin the search for information without determining a fixed sample. The individual will stop searching when a consecutive streak of either positive or negative pieces of information is found, three consecutive positive opinions for example.

The stopping rule selection theory proposes that each individual might use different stopping rules given time and cognitive efforts available (Fific \& Buckmann, 2013). That is because there is no evidence that one single stopping rule can account for all responses. According to Fific and Buckmann (2013) each individual will search a decision operative space in which the rules and values are stored. Given a decision situation the individual will then retrieve a stopping rule - a process that the authors call cast-net retrieval. Much like fishing, each individual will select a space and a net size to cast and retrieve a stopping rule that will be applied. What is considered in order to cast a net in the decision operative space is the level of uncertainty in the environment, time frame, cognitive demand, and accuracy expectancy (Fific \& Buckmann, 2013). After the stopping rule is selected, the individual will then proceed to collect information and finally decide.

Other elements also influence the information acquisition process. Frey et al. (2014) found that a facial expression of fear or the subjective feeling of fear both causes the individual to search for more information. Söllner et al. (2014) discovered that when intruding incompatible information appears, individuals trained in the TTB heuristic would not stop searching for information when they were supposed to if following TTB. Individuals rather adapted their information search, choice and confidence judgment processes to 
the content of such intruding information. Motivation can also play a role in information acquisition and goal pursuit (Ballard, Yeo, Loft, Vancouver \& Neal, 2016). The amount of information available and acquired by each individual may increase or decrease complexity levels in the decision situation, much like what happened with the intruding information.

\section{Complexity}

Uncertainty, according to Nobre, Tobias, and Walker (2010), is intimately connected with complexity. As was already discussed, uncertainty is closely related to the amount of information acquired and processed by a given individual and the understanding of the situation at hand. With more information about a situation it is easier for an individual to calculate probabilities (either objective or subjective) and assess risk levels (Taghavifard et al., 2009). However, the more complex the environment or the task presents itself, the more difficult it is to collect and interpret information, and reduce residual uncertainty.

Brum (2011) states that complex systems are affected by the emergence of phenomena resultant of nonlinear interrelationships that may throw the system out of its natural balance requiring that this disorder created must fall back into order by self organization. The decision-making process may share such description. After all, one needs to make a decision in order to reorganize some part of a greater system (that can be the individual itself or a group, say a family unit) that was shaken out of a state of balance by the emergency of a circumstance, fact or phenomena. In simpler words, one needs to eat if one feels hungry. The greater system that is the body needs nourishment. Food intake must be provided. At this point the system is in disorder, out of homeostasis. Self organization occurs when that individual eats something. The decision in this case is as simple as choosing what to eat.

A human being is an open system that also participates in other equally open systems. There is a perpetual exchange of information, matter and energy (Brum, 2011) between the outside world and the inside part of any system. The higher the level of exchanges, the more complex the system is. Nobre et al. (2010) state that systems may vary in structure and interactions. They may be extremely simple and stable, or complex and dynamic. At the core of the interactions between the parts of a system are its abilities, defined by Nobre et al. (2010) as cognition, learning and knowledge capabilities. The greater the complexity of the environment, more information and cognitive abilities must the individual have in order to make an adaptive decision.

Campbell (1988) conceives of complexity in three ways. The first regards complexity as a psychological experience. The main point in this view is that the reactions of the individual to the task outweigh the characteristics: increases in task complexity may tax cognitive resources and lead individuals to employ strategies that minimize the amount of information considered. Experience with the decision context may minimize the impact of complexity, however, with knowledge and strong preferences leading to a more focused, information-minimizing search (Queen, Hess, Ennis, Dowd, \& Grühn, 2013). Individuals cope with complexity within the decision process by simplifying the dimensions existent in the problem. They essentially withdraw certain dimensions in order to diminish the amount of information and calculations required to consider the alternatives and outcomes.

A second aspect of complexity is the opposite of the first, with complexity as an interaction between the person and her abilities in relation to the task demands. As stated by Simon (1959), "As the complexity of the environment increases, or its speed of change, we need to know more and more about the mechanisms and processes that economic man uses to relate himself to that environment and achieve his goals" (p. 279). The way the task presents itself to the individual and also the way it is perceived are important to determine the decision-making conditions. Problem representation (Pretz et al., 2003) and the framing effect (Kahneman, 2011) are examples. If a task presents itself in an ill structured manner or the decision maker does not have sufficient ability to understand the facts pertaining to a problem, the level of perceived complexity will be higher.

From a third and final perspective, complexity is an objective task characteristic (Campbell, 1988). In this view, complexity is related to and influenced by a myriad of task characteristics. How a task is set up ranging from information load, number and magnitude of stimulations, existence of subtasks and conflicting or non-conflicting paths and possible outcomes, among other qualities, may cause variations in complexity levels. All of those can require high cognitive demands from an individual. The most important fact in this perspective is that the task can present itself in many ways and the configuration of the task will 
increase complexity levels (Campbell, 1988). There is no way to gauge which of the task characteristics will determine an increase and/or decrease in complexity. Each particular task may present itself with a combination of any characteristics. For example, a task can have a great amount of information and multiple paths for the decision maker to choose from. That alone can set up a highly complex environment. However if the outcomes for each alternative are easily distinguishable and the decision maker has a very clear set of preferences than there should not be a significant amount of complexity, given that the information load and the multiple paths will not matter, the preferred outcome will be easily chosen.

Campbell (1988) also proposes an integrative framework for complexity. It would arise in the presence of various paths to reach the desired state, the presence of multiple outcomes, the presence of conflicting interdependence within the paths and the presence of uncertain links among paths and outcomes. All of these require acquisition and analysis of information. The information load, diversity and rate in which it changes are closely related to the task attributes and very influential on perceived task complexity (Campbell, 1988; Di Caprio et al., 2014). The term perceived is used because acquirement and analysis of information depend on cognitive capacity and performance by the decision maker, so a given individual might perceive a task as very complex whereas another individual might perceive it with a low complexity level. In essence, complexity depend both on subjective and objective criteria regarding characteristics pertaining to the task and the individual and its relation to the task. The decision-making process can suffer from the intricate complexity amongst the alternatives while considering each path that can be chosen and the consequences of that action (Taghavifard et al., 2009).

\section{Decisions in dynamic scenarios}

The elements and characteristics of decision-making discussed so far (uncertainty, risk, information acquisition and complexity) are prevalent in the decision process. In a given situation there might be varying levels of uncertainty, information load imposed, satisficing threshold, risk levels, etc. Real world situations are constantly changing and those changes might significantly alter the characteristics of the situation. In other words, they are mostly dynamic, rather than static. Decision makers must know when they are facing dynamic environments in order to adjust decision strategies and processes.

Dynamic decisions occur because of certain environmental elements that must be considered, such as importance, time frame and degree of individuality (Gomes, 2007). Dynamic changes in decision scenarios can produce changes in perceived expectations of rewards (Mushtaq, Stoet, Bland \& Schaefer, 2013), for example. The objective characteristics of the task in complex systems also may turn a static decision scenario into a dynamic one. Given the information load, number of alternatives and the rate of change of information, a decision can become more intricate. Lastly, each individual's preference will have a role to play (Simon, 1955).

We may consider a decision such as buying shampoo. One person may not care that much about brand, specific type of hair that the shampoo attends to, perfume, or other additional characteristics it may have. In that case, the choice is fairly easy, it might either be a purchase following an advice or a price based one. That is a situation with low risk of hazard, but also low opportunity. There is no need to calculate probabilities of outcomes since they will not end in drastically different perceived outcomes. Although high in uncertainty about different characteristics, the information the individual has is enough in order to make a decision. Satisfaction should be attained easily since this decision is of no greater importance and pertains only to this individual.

In order to evaluate how dynamics may play a role even in simple decisions, let us regard a consumer behavior scenario. A different person needs shampoo. She needs a specific type of shampoo given her hair type. Moreover, this person needs the shampoo to have certain vitamins and it must have a nice perfume. Any brand cannot suffice, it must be one that is renowned, however it must be within a reasonable price. When asking some friends, all kinds of advices were given, some were positive about some brands, some were negative about other brands. After all advices she got down to a list of mainly four potential brands. This scenario portraits a more dynamic environment; uncertainty is higher, risk of hazard (both physical and emotional) is higher, complexity given the information load and dimensional features is also higher and finally the satisfaction threshold is fluctuating (this person might settle for a more expensive brand given the benefits and vice-versa). Importance here is great, as this person values her hair very much. Even with all 
the information, the individual summed up a list of four brands. That means multiple paths and multiple outcomes are available. The advices she received were not enough to allow her a single path choice. In this case, the individual is susceptible to new, conflicting or not, information. A single advertisement or a new advice from a friend or professional can affect the whole process. The possible brands the individual might consider as a viable option can either increase or decrease.

Choice in real life are dynamic with interactions between different stages and information (Halpern \& Leung, 2015). That interaction and the results that come from it changes criteria linked to the decision and the environment. Some strategies proposed by game theory and applied to everyday decision-making can serve as an example. The case of brinkmanship, or pushing dangerous events to the limit of disaster one example (Dixit and Nalebuff, 2008). In this situation, agents use brinksmanship in order to force the other party to accept their terms. In most cases, the strategy is only used as a last resort. When this strategy is used uncertainty and risk change dramatically.

An example of such changes goes as follows: two countries are negotiating the end of a trade embargo. Peaceful negotiations are happening and at this stage there are several scenarios that can be played and levels of deals that can be reached. So far, risk and uncertainty remain at an economic level. Now suppose one of the nations gets tired of negotiations and starts using brinksmanship to try and seal the deal on its own terms. Should the opposing nation decline the terms, there will be a nuclear strike on its cities. Now, what was once an economic discussion is also a matter of homeland security. Also, where there had been hundreds of possible combinations of a deal, now there are only a few: the opposing nation accepts the deal and there is no nuclear war; the opposing nation may call on the threat and either receives a nuclear strike or see that the threat was actually a bluff, in which case the scenario will dramatically turn once again. From a single unilateral decision, there has been a large change in the environment, time necessity, uncertainty and risk within the whole decision.

Bland and Schaefer (2012), in the discussion about the S-R-O models, further explain the actions of a dynamic decision scenario. They propose a scenario where people would choose a particular restaurant because they know that roughly about eight out of ten times they go there their favorite dish will be available.
That will remain true and steady, given that the scenario show no signs of possible changes. However, Bland and Schaefer (2012) propose, imagine that the chef is not the same anymore. Thus what was once a $80 \%$ chance of having the favorite dish served is now different (and uncertain) because there is little information about the new chef. A dynamic change altered most of the decision-making settings for this particular type of problem. These changes may elicit an expectation of decrease in rewards (Mushtaq et al., 2013) which may change the whole decision process.

Dynamic and/or static scenarios are part of any decision. They can emerge via aspects that can change given environmental factors involved in the scenario. As it was seen, dynamic scenarios will required greater cognitive capacity and information interaction from the decision makers. Many times, given the characteristics and requirements brought forward by dynamic or static decision-making, individuals will tend to choose different strategies in order to resolve the problem at hand. Much like the cast net retrieval (Fific \& Buckmann, 2013), decision makers will search for known and/or comfortable strategies in order to resolve the different aspects involved and proceed to a decision.

\section{Strategies in decision-making}

Decisions involve a choice amongst several alternatives. Before the choice is actually made individuals must choose the criteria on which to rely in order to pick an alternative. The larger the set of alternatives and the criteria available, the more complicated and cognitively demanding is the process of choosing. In order to try and solve problems or to reach a decision, individuals resort to strategies based on methods that they may not even be aware of. Some of these behaviors and strategies violate the assumptions made by normative decision theories. Amongst such strategies are those discussed by game theory, heuristics, and multiattribute decision-making.

Dixit and Nalebuff (2008) explain several strategies used in game theory, from the most basic ones, like in the prisoner dilemma, to more complex ones such as creating a political strategy for an election campaign. Mainly used in negotiation of all sorts, it involves information acquisition and an alleged knowledge of the opponent's action and reaction to a given decision or environmental setting. Game theory proposes very objective views regarding a scenario analysis. There are tools that can be used: decision trees, payoff matrixes 
and backward reasoning. A decision tree is simply a graphical way to represent a problem and the paths available. It can represent the actions both individually or of every individual in the game. With the decision tree, for visualizing the paths and outcomes, and the payoff matrix, for weighting the payoffs for each outcome, the decision maker can resort to backward reasoning to help in the decision-making process.

Game theory rests on a mathematical foundation. In the prisoner dilemma, for instance, it is mathematically proven that it is in the best interest of both players not to confess to the crime (that way both will suffer the smaller conviction time). In another application, it is often thought that penalty kicks in soccer are something of a "lottery", meaning one can never precisely say if it will be converted in a goal or not. However, it is possible to calculate a more probable manner to both kick and defend a penalty kick. But still there are psychological and emotional elements to every decision process. Those may come into action given the different levels of the aspects involved in the decision scenario.

Even though many strategies can be followed in a decision process, many times people choose to use cognitive shortcuts or heuristics. Heuristics are a well known subject of study in the judgment and decisionmaking field. Most famously studied by Amos Tversky and Daniel Kahneman, it is one of the most important topic related to decision-making. Heuristics are a sort of shortcut to reach a decision, many times violating the assumptions of normative theories and game theory. They are based on certain criteria and sensible to how the problem is presented to the decision maker. Representativeness, availability, adjustment and anchoring (Tversky \& Kahneman, 1974) are the main heuristics individuals may use. Each one of these heuristics may lead to cognitive biases that might hinder the decision itself. Detailed discussions of this topic can be found in Tversky and Kahneman (1974), Brighton and Gigerenzer (2012), Gigerenzer (2000), Hogarth (1991), Kahneman (2011), Pachur, Todd, Gigerenzer, Schooler, and Goldstein (2011). As it pertains to this essay, heuristics and biases can be considered as one of the strategies individuals indulge in order to decide in a scenario comprising the factors discusses thus far.

Mintz, Geva, Redd and Carnes (1997) discuss two main strategies, one alternative-based, more complex and demanding involving compensatory tradeoffs; and one dimension-based, less complex and demanding involving non-compensatory tradeoffs. Information has a pivotal role in the strategy selection regarding the static or dynamic environment where the problem is set upon. The authors developed a platform that can be used to trace the process of analyzing the strategy choice. For each problem there is a matrix composed of the alternatives and decision dimensions. By conducting an experiment they found that decision makers consider different strategies to arrive at a decision. They first start with cognitive heuristics to diminish the number of possible alternatives in a dimension basis and then conduct an alternative based decision.

\section{Decision-making Processes: Integrating The Concepts}

Deciding involves weighing the potential outcomes, their consequences and the probability embedded in any course of action (Taghavifard et al., 2009). In order to do so, an individual must be able to acquire and process several pieces of information that may come in several types and amounts. The information obtained during the decision process allows the decision maker to assume or calculate with more accuracy the alternatives, outcomes and mainly the probabilities of them happening (Taghavifard et al., 2009). However, there is no need to choose one single alternative. Given the right amount of information and calculation one can, obeying a set of preferences, assemble a mix of alternative choices.

If one is to decide under utter uncertainty, it is likely that risk, criteria and alternative assessment will be mainly based on the individual's attitude towards the unknown (Taghavifard et al., 2009). Tversky and Kahneman (1992), Ariely (2008), Zhan, Gu, Wu, Broster, Luo, Jiang \& Luo (2013) amongst others provide some examples of behavior under some degrees of uncertainty. Normally, individuals will use different strategies in order to resolve the problem. Some strategies, if ill planned, may lead to biases that will hinder the decision process. Many of the mistakes made by individuals' lies on the fact that they are not able to promptly and properly calculate risks (be that by an emotional or cognitive incapacity).

Taghavifard et al. (2009, p.6) state that in a risky scenario individuals make mistakes mainly because of "false assumptions, not having an accurate estimation of the probabilities, relying on expectations, difficulties 
in measuring the utility function and forecast errors". Those aspects are closely related and an actual effect of fluctuating levels of uncertainty, information acquisition, cognitive processing and behavior. As far as complexity goes, the integrative framework proposed by Campbell (1988) covers some important points, mainly because of its relationship with the task as presented to the individual. This framework proposes multiple paths and outcomes and also considers the conflicts that may emerge from these paths. The information load, information diversity and the rate of information change are thus vital characteristics to the decision process. Combining these characteristics results in higher cognitive demands in order to analyze the paths and calculate possible outcomes, its probabilities and risks associated.

So far we have discussed that decision-making is comprised of different factors. Studies in the area tend to consider those factors separately. However, we posit that, given what was seen so far it is possible to assume that the decision process can be influenced by a combination of those factors, and that they may vary in intensity. The factors posited as components in the decision process are the ones discussed above: uncertainty, risk, information acquisition, complexity (composed by information load, information diversity, and rate of information change), static/dynamic scenarios, and decision strategies. The factors may interact with each other in different ways and degrees, however we posit that decisions will in most cases be comprised these interactions.

They can be differentiated in two separate albeit complementary groups: key factors and environmental factors. The key factors are those that will be present in any decision whatsoever. They are risk, and uncertainty. As was discussed above, in every decision there will be some measure of uncertainty and risk. In order to solve the key factors, individuals will be prompted to use their cognitive capacities in order to understand the problem as it is presented to them. Scenario presentation is the first step of the information acquisition process. They will promote the need for information acquisition and will be modulated by the results of the process, thus influencing in the perceived complexity and other characteristics. As individuals perceive the scenarios, they will have enough information to begin the acknowledgment of the environmental factors.

The environmental factors are those that can modulate or be modulated by factors external to the individuals.
Perceived complexity can be higher or lower given the knowledge possessed by the individual. However, it can also vary given factor that are not controlled by them. Information load diversity and rate of change are sometimes modulated by other agents or events. They will influence the decision process as a whole. As it was seen before, higher complexity can lead to procrastination and suboptimal decisions. Perceived complexity is closely linked with information acquisition. The process of gathering information about the scenarios and alternatives will incur in changes not only on the key factors, but also on other environmental factors as well. Optimal amounts of information will provide the individual with the best levels of uncertainty, risk, complexity and scenario state available. This may facilitate the choice of the decision strategy or strategies.

Another environmental factor is the dynamism - or lack thereof - of the decision scenarios. As it was discussed above, the state of a given scenario can drastically alter the levels of the factor (both key and environmental). Dynamic scenarios will normally manifest themselves as high in complexity and may hinder the information acquisition process. These changes will modulate uncertainty and risk calculation, but not always it will make them seem higher. For an expert, a dynamic scenario might present itself as an easily solvable problem, given that the individual will have enough knowledge to act almost automatically to the cues presented.

In this sense, it is possible to assume that in a given decision scenario the key and environmental factors are somewhat connected and can modulate or be modulated by each other. Moreover, all factors may or may not be in play at the same time (Campbell, 1988; Di Caprio et al., 2014; Dixit \& Nalebuff, 2008; Gomes, 2007; Kahneman, 2011; Simon, 1959; Taghavifard et al., 2009). There still is a gap in theoretical and empirical evidence to clearly determine if those connections are actually in play and the degree and direction in which the modulations occur. We propose in Table 1 a suggestion of how the factor may be connected. It depicts the factors and how they can vary and or be affected by each other. It is important to note that the factors may repeat given the different characteristics of the environment or task.

A first aspect to be considered relates to environmental elements. They may shift the environment from static to dynamic. The higher the intensity of the elements, the more dynamic the environment presented to the 
decision maker will be. If a scenario is dynamic it poses a more pressing challenge on the decision maker in order to successfully respond to the elements. Brehmer (1992) states that the study of dynamic decisionmaking needs to attain more attention in psychological research although it is somewhat difficult to fit dynamic situations in normative standards, and experimental methods might lack the proper power to do so. Moreover, environmental elements, such as time constraints, influence the way the decision maker acquires information (Di Caprio et al., 2014). Without information the decision maker will have his capacity to infer probabilities regarding the decision at hand severely hindered.

Organizational settings present relevant examples of highly dynamic decision problems (Gomes, 2007). Consider a group that is responsible for drafting the budget for the next fiscal year in a company. The individuality degree is very low, the decision is made in a group setting and affects a large number of people. It is of great importance because it represents the immediate future of the company. It has a tight time frame, it is normally done with no more than a couple of months up until the deadline. The information load is considerable, and data needs to be considered from each and every part of the company. From Human Resources to macroeconomic indexes, every bit of information needs to be considered. Moreover, information may change rapidly. New laws, economic policies, bad performance, employee strike, are among a very wide range of possible changes that can occur. Given the amount of information load and the rapid rate of change of information there are literally millions of possible alternatives combinations that can be reached (Campbell, 1988). Finally, the satisfaction threshold is very hard to reach. Every stakeholder has a specific satisficing threshold. The scenario depicted is highly dynamic and is one that happens at least every year for most of the organizations around the world.

This scenario necessarily entails that the group will probably never acquire enough knowledge in order to diminish residual uncertainty to a minimum and make a decision with risk and probability properly calculated and weighted amongst the alternatives. In order for this group to reach a decision they will be forced to acquire a great amount of information from data of the year's performance and of economic indexes. After the information is acquired they will have to process that information and also calculate what they mean in order to forecast scenarios and provide possible alternatives for the company's future. That requires great cognitive capacity. Since high residual uncertainty is the most likely depiction of uncertainty, the group will base its choice on subjective probabilities highly influenced by each member preferences and past knowledge. But in order to reach a decision all risks must be calculated, since a bad year for a company can reflect great hazards in all dimensions and a good year may present great opportunities for everyone. Alas, in this scenario risks are very hard to calculate and predict. In order to solve such a problem the group will certainly use different strategies.

Table 1 . Factors that influence the decision process

\begin{tabular}{ccc}
\hline Environmental factors & Static Environment & Dynamic Environment \\
\hline $\begin{array}{c}\text { Importance, time frame, information } \\
\text { load, number of alternatives, rate of } \\
\text { change of information and satisficing } \\
\text { threshold }\end{array}$ & $\begin{array}{c}\text { Enough knowledge should be } \\
\text { attained easily }\end{array}$ & $\begin{array}{c}\text { Enough knowledge should be } \\
\text { hard to attain }\end{array}$ \\
\end{tabular}

Information load, number of alternatives, rate of information change and satisficing threshold

Importance, individuality degree, information load, number of alternatives, rate of information change and satisficing threshold

Low residual uncertainty

High residual uncertainty

Proximal to a deterministic model (risk can be calculated objectively)
Proximal to a pure uncertainty model (risk will be calculated subjectively) 
Importance, time frame, individuality degree, information load, number of alternatives, rate of change of information and satisficing threshold

Importance, time frame, individuality degree, information load, number of alternatives, and rate of change of information

Information load, number of alternatives, and rate of information change

Importance, time frame, information load, number of alternatives, and rate of information change
Less cognitive capacity required

More cognitive capacity required
Little information acquisition needed

Expected utility axiom
Great information acquisition required

Subjective expected utility axiom
Single decision strategy Poliheuristic decision strategy

The opposite can also be true. A decision can be as simple as choosing what to eat for breakfast on a Sunday morning. There is no pressing importance, each person can take as much time as they want, the set of preferences regarding food is quite explicit and firm therefore satisficing threshold should be fairly easy to attain. There is also no need for much information and there is little probability of it changing. This static environment produces very low residual uncertainty (Pretz et al., 2003) given that each person knows what they like to eat for breakfast, there will be little risk of hazard nor does it present a huge opportunity. There is little need for large consumption of cognitive processing resources. The decision maker should simply follow a simple maximization strategy: will I have toasts and coffee or pancakes and milk?

\section{Concluding Remarks}

In this article we aimed at discussing a theoretical approach to decision-making in view of an updated collection of crucial aspects and/or parameters. Those are prime candidates for a possible integrative, empirically testable model in the near future, given the amount of novel evidence amassed. A first approximation to such a model proposes decision structure to be influenced by mutually influencing factors uncertainty, risk, and complexity. Moreover, those factors are influenced by the importance, time frame, individuality degree, levels of information and rate of information change involved in the decision, what is conceptualized here as environmental factors. Variations in the levels of those factors can modulate or be modulated by information acquisition, levels of perceived complexity and dynamism in the decision scenario. As it was proposed in Table 1, there are several ways in which the factors can vary the levels of other factors and thus influence the result of a decision.

Decisions are complex and intricate phenomena and there is a lack in the theoretical and especially experimental literature as to the integration of the different factors that play a pivotal role in a decision. This fact is supported by the difficulty in properly managing and controlling a scenario with large amounts of variables in experimental conditions. Most studies tend to focus on one or two of the factors in an experiment (Mushtaq et al., 2013; Bland \& Schaefer, 2012; Di Caprio et al., 2014). As we tried to discuss, there is a possible connection between the factors that is, to the best of our knowledge, somehow overlooked by theoretical research and experimental paradigms. We posit that the insertion and manipulation of different factors can shed light and aid the explanation of the decision process as a whole. Moreover, it can help explain deviations from normative theory and the use of heuristics and biases (Tversky and Kahneman, 1992). 
A decision is comprised of a myriad of stimuli and actions. As individuals decide, they tend to search for information in different manners (Fific \& Buckmann, 2013). They will be confronted with varying levels of uncertainty and risk (Taghavifard et al., 2009). As information is processed, complexity and dynamism in the scenarios may arise (Campbell, 1988; Halpern \& Leung, 2015). Key and environmental factors are connected in such a manner that it is possible to state that they are present, jointly, in any decision, ranging from the more mundane to the most intricate one. The importance of the integrated view posited in this essay is that the effects of the factors may be perceived in the optimality of the decision. Moreover, there is a limited amount of cognitive capacity that each individual will possess in order to solve a given decision (Simon, 1995). Given these constraints, it is imperative that the decision process would be analyzed in an integrated fashion, in order to better determine which factor (or combination of) will prove to be most influential in a given decision scenario.

Technological and theoretical advancements might enable researchers to attempt to further illustrate the interactions and modulations occurring with the factors within a decision situation. This claim is made given the importance that uncertainty, risk and complexity play on decisions. Since they are mainly modulated by environmental factors and have a great impact on the psychological and cognitive processing of individuals facing a problem, it is important that researchers start thinking about decisions in a wider picture. This is what this essay proposes. An integrative view of decision factors as a theoretical start. It is a first opening to an approach where decisions need to be measured as a whole. Most studies thus far look at the factors in a separated way. However, as in any complex system, the sum of its parts does not equal the whole. The unity of a decision situation can be different, more complex and intricate. A miscalculation of risk, a choice of a heuristic or other decision strategy or the biases that emerge, can have different loci if the whole is considered. It might not be just a question of cognitive capacity or lack of information. There may be time constraints or quality of information, for example.

Through this essay we intended to contribute to evolving trends in theoretical, methodological, and practicalissues regarding the study of decision-making, as well as to management practice. The contributions to theory and practice were discussed above, as an integrative way to the devising of decision scenarios in experimental paradigms for empirical research. Contributions to management practice lies on the fact that managers and collaborators alike can benefit from this integrated view. Understanding the different aspects of decision-making and how they interact can further aid the individual and social decision-making processes within organizations. That might lead to improved decision training techniques, groups and team formation, personnel selection, amongst other important issues. It is possible, we propose, that with this integrated view, companies will be able to perfect training programs in order to educate individual and group decision making given the many possible integration between the factors. It will be possible to navigate through decision scenarios in such a manner as to better understand its factors, facilitating strategy and heuristic choice (Kahneman, 2011) and a more optimal definition of satisficing levels (Simon, 1955). We believe these advancements will promote a easier path to more optimal decisions and the adequate choice of decision strategies.

Finally, this paper proposes a new, in-progress, encompassing approach to observe decision-making and possibly advance its understanding. Further studies are necessary in order to further improve the theoretical outline proposed here. Moreover, there is the attempt to create and/or adapt experimental decision paradigms in order to include more factors in a rigorous and operationally proper way.

\section{References}

Ariely, D. (2008). Previsivelmente irracional. Rio de Janeiro: Elsevier.

Armbruster, B., \& Delage, E. (2015). Decision making under uncertainty when preference information in incomplete. Management Science. 61(1): 111-128. http://dx.doi.org/10.1287/mnsc.2014.2059

Ballard, T., Yeo, G., Loft, S., Vancouver, J.B., Neal, A. (2016) An integrative formal model of motivation and decision making: the MGPM. Journal of Applied Psychology 101: 1240-1265. doi: 10.1037/ ap10000121

Bland A. R., \& Schaefer, A. (2012). Different varieties of uncertainty in human decision-making. Frontiers in neuroscience, 6: 1-11. doi: 10.3389/ fnins.2012.00085. 
Brehmer, B. (1992). Dynamic decision making: human control of complex systems. Acta Psychologica, 81(3), 211-41.

Brighton, H., \& Gigerenzer, G. (2012). Homo Heuristicus: Less-is-More Effects in Adaptive Cognition. The Malaysian Journal of Medical Sciences : MJMS, 19(4), 6-16.

Brocas, I. (2012). Information processing and decision-making: evidence from the brain sciences and implications for economics. Journal of Economic Behavior \& Organization. 83: 292-310.

Brum, M. C. (2011). Las ciencias sociales y el problema de la complejidad. Argumentos (México, DF), 24(67), 15-35. Retrieved from http:// www.scielo.org.mx/scielo.php?pid=S0187$57952011000300002 \&$ script $=$ sci_arttext.

Camerer, C., \& Weber, M. (1992). Recent developments in modeling preferences: Uncertainty and ambiguity. Journal of Risk and Uncertainty, 5(4), 325-370. doi:10.1007/BF00122575.

Campbell, D. J. (1988). Task Complexity: A Review and Analysis. The Academy of Management Review, 13(1), 40. doi:10.2307/258353.

Courtney, H., Kirkland, J., \& Viguerie, P. (1997). Strategy under uncertainty. Harvard Business Review, (December), 81-90.

Di Caprio, D., Santos-Arteaga, F. J., \& Tavana, M. (2014). Information acquisition processes and their continuity: Transforming uncertainty into risk. Information Sciences, 274, 108-124. doi:10.1016/j. ins.2014.02.144.

Dixit, A., \& Nalebuff, B. J. (2008). The art of strategy: a game theorist's guide to success in business \& life. New York: W. W. Norton \& Company.

Fifi $\square$, M., \& Buckmann, M. (2013). Stopping Rule Selection (SRS) Theory Applied to Deferred Decision Making. In Proceedings of the 35th Annual Meeting of the Cognitive Science Society (pp. 22732278). Retrieved from http://mindmodeling.org/ cogsci2013/papers/0415/paper0415.pdf.

Frey, R., Hertwig, R., \& Rieskamp, J. (2014). Fear shapes information acquisition in decisions from experience. Cognition, 132(1), 90-99. doi:10.1016/j. cognition.2014.03.009.
Gigerenzer, G. (2000). Adaptive thinking: Rationality in the real world. New York: Oxford University Press.

Gomes, L. F. A. M. (2007). Teoria da decisão. São Paulo: Thomson Learning.

Halpern, J. Y., \& Leung, S. (2015). Minimizing regret in dynamic decision problems. Theory and Decision. 81(1): 123-151.

Hogarth, R. M. (1991). Judgment and choice (2nd ed.). New York: Wiley-Interscience.

Huang, Y., Liu, L., \& Qi, E. (2016). The dynamic decision in risk-averse complementary product manufacturers with corporate social responsibility. Kybernetes, 45(2), 244-265. http:/ /dx.doi. org/10.1108/K-01-2015-0032.

Kahneman, D. (2011). Thinking, fast and slow. New York: Farrar, Straus and Giroux.

Knight, F. H. (1921). Risk, uncertainty and profit. Boston: Houghton Mifflin Co.

Li, Y., Baldassi, M., Johnson, E. J., \& Weber, E. U. (2013). Complementary cognitive capabilities, economic decision making, and aging. Psychology and Aging. 28(3): 595-613. doi: 10.1037/a0034172.

Maitland E, Sammartino A (2014) Decision making and uncertainty: the role of heuristics and experience in assessing a politically hazardous environment. Strategic Management Journal 36:1554-1578. https://doi.org/10.1002/smj.2297

Meder, B., Le Lec, F., \& Osman, M. (2013). Decision making in uncertain times: what can cognitive and decision sciences say about or learn from economic crises? Trends in Cognitive Sciences, 17(6), 257-60. doi:10.1016/j.tics.2013.04.008.

Mintz, A., Geva, N., Redd, S. B., \& Carnes, A. (1997). The Effect of Dynamic and Static Choice Sets on Political Decision Making: An Analysis Using the Decision Board Platform. The American Political Science Review, 91(3), 553-566. Retrieved from http://links. jstor.org/sici?sici=0003-0554(199709)91:3<553:TEO DAS>2.0.CO;2-\#.

Mushtaq, F., Stoet, G., Bland, A.R., and Schaefer, A. (2013) Relative changes from prior reward contingencies can constrain brain correlates of outcome monitoring. PLoS ONE, 8(6), e66350. 
Neumann, J. von, \& Morgenstern, O. (2007). Theory of Games and Economic Behavior (Commemorative Edition). doi:10.2307/j.ctt1r2gkx.

Nobre, F. S., Tobias, A. M., \& Walker, D. S. (2010). A New Contingency View of the Organization : Mananging Complexity and Uncertainty Through Cognition. Brazilian Administration Review, 7(4), 379396.

Pachur, T., Todd, P. M., Gigerenzer, G., Schooler, L. J., \& Goldstein, D. G. (2011). The recognition heuristic: a review of theory and tests. Frontiers in Psychology, 2(July), 147. doi:10.3389/fpsyg.2011.00147.

Pretz, J. E., Naples, A. J., \& Sternberg, R. J. (2003).

Recognizing, defining and representing problems. In The Psychology of Problem Solving. Cambridge University Press.

Preuschoff, K., Mohr, P. N., \& Hsu, M. (2013). Decision making under uncertainty. Frontiers in Neuroscience. 7: 1-2. doi:10.3389/fnins.2013.00218

Queen, T. L., Hess, T. M., Ennis, G. E., Dowd, K., \& Grühn, D. (2013). Information search and decision making: The effects of age and complexity on strategy use. Psychology and Aging, 27(4), 817-824.

Savage, L. J. (1955). The foundations of statistics. Journal of Consulting Psychology (Vol. 19, pp. 237-237). doi:10.1037/h0038916.

Simon, H. A. (1955). A Behavioral Model of Rational Choice. The Quarterly Journal of Economics, 69(1), 99. doi:10.2307/1884852.

Simon, H. A. (1959). Theories of Decision making in economics and behavioral science. The American Economic Review, 49, 253-283. doi:10.2307/1809901.

Söllner, A., Bröder, A., Glöckner, A., \& Betsch, T. (2014). Single-process versus multiple-strategy models of decision making: Evidence from an information intrusion paradigm. Acta Psychologica, 146, 84-96. doi:10.1016/j.actpsy.2013.12.007.

Stern, E. R., Gonzalez, R., Welsh, R. C., \& Taylor, S. F. (2010). Updating beliefs for a decision: neural correlates of uncertainty and underconfidence. The Journal of Neuroscience, 30(23), 8032-41. doi:10.1523/ JNEUROSCI.4729-09.2010.

Taghavifard, M. T., Damghani, K. K., \& Moghaddam, R. T. (2009). Decision Making Under
Uncertain and Risky Situations. In Enterprise Risk. Management Symposium Monograph Society of Actuaries. Chicago, IL.

Tversky, a, \& Kahneman, D. (1974). Judgment under Uncertainty: Heuristics and Biases. Science (New York, N.Y.), 185(4157), 1124-31. doi:10.1126/ science.185.4157.1124.

Tversky, A., \& Kahneman, D. (1992). Advances in prospect theory: Cumulative representation of uncertainty. Journal of Risk and Uncertainty, 5(4), 297323.

Yoe, C. (2012). Primer on risk analysis: decision making under uncertainty. Boca Raton: CRC Press.

Zhang, D., Gu, R., Wu, T., Broster, L. S., Luo, Y., Jiang, Y., \& Luo, Y. J. (2013). An electrophysiological index of changes in risk decision-making strategies. Neuropsychologia, 51(8), 1397-1407. doi:10.1016/j. neuropsychologia.2013.04.014. 